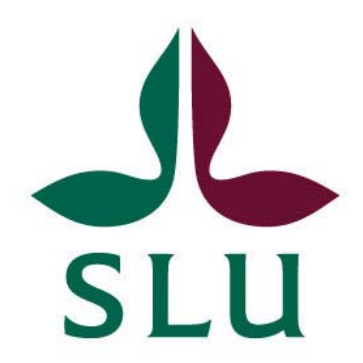

This is an author produced version of a paper published in Remote Sensing of Environment.

This paper has been peer-reviewed but may not include the final layout and proof-corrections by the publisher.

Citation for the published paper:

Milenković, Milutin; Schnell, Sebastian; Holmgren, Johan; Ressl, Camillo; Lindberg, Eva; Hollaus, Markus; Pfeifer, Norbert; Olsson, Håkan. (2017). Influence of footprint size and geolocation error on the precision of forest biomass estimates from space-borne waveform LiDAR. Remote Sensing of Environment. 200, pp. 74-88. https://doi.org/10.1016/j.rse.2017.08.014.

Published with permission from: Elsevier

(C) Elsevier, 2017. This manuscript version is made available under the CCBY-NC-ND 4.0 license http://creativecommons.org/licenses/by-nc-nd/4.0/

This publication is openly available through SLU publication database, http://urn.kb.se/resolve?urn=urn:nbn:se:slu:epsilon-p-92033 


\title{
Influence of Footprint Size and Geolocation Error on the Precision of Forest Biomass Estimates from Space-Borne Waveform LiDAR
}

Milutin Milenković a *, Sebastian Schnell ${ }^{\text {b,c }}$, Johan Holmgren ${ }^{b}$, Camillo Ressl a, Eva Lindberg ${ }^{\text {b }}$, Markus Hollaus a, Norbert Pfeifer ${ }^{\text {a }}$, Håkan Olsson ${ }^{b}$

${ }^{a}$ Department of Geodesy and Geoinformation (GEO),Technische Universität Wien, Gußhausstraße 27-29, 1040

Venna, Austria

${ }^{\mathrm{b}}$ Department of Forest Resource Management, Swedish University of Agricultural Sciences, SLU Skogsmarksgränd, Umeå SE-90183, Sweden

${ }^{\mathrm{c}}$ Forest Inventory and Remote Sensing, Faculty of Forest Sciences, University of Goettingen, Buesgenweg 5, 37077

Goettingen, Germany

* Corresponding author. Tel.: +43 (1) 58801 -12254; fax: +43 (1) 58801 -122 99E-mail address:Mi-

lutin.Milekovic@geo.tuwien.ac.at

Published 2017 in Remote Sensing of Environment 200, 74-88

\begin{abstract}
Space-borne LiDAR systems can potentially assist large-area assessments of forest resources, in particular when a subset of the acquired LiDAR footprints is combined with field surveys of forest stand characteristics at footprint location. When combined, space-borne LiDAR geolocation error and the footprint size may however have considerable effects on the estimation accuracy of forest stand variables, such as aboveground biomass (AGB). The aim of this study was to draw recommendations for future space-borne LiDAR systems, which should deliver data for unbiased AGB assessments. The recommendations were drawn from AGB estimations based on space-borne LiDAR waveforms simulated over a 1300 ha large study site in southern Sweden. Large-footprint, nadir-looking satellite waveforms were simulated by stacking individual small-footprint, airborne LiDAR waveforms observed near a predefined sampling pattern. The stacked waveforms, represented by their metrics, were used as input for a two-phase systematic sampling in combination with model-assisted estimation or hybrid inference for estimating AGB and its variance. The second-phase sample included 264 inventory plots, whereas the first-phase sample included 1010 sample locations, where satellite waveforms were simulated. After simulating satellite waveforms with different footprint sizes and analyzing the AGB variance, the recommendation is to have a footprint size that is similar to the size of the field plots used for collecting reference data, i.e. $20 \mathrm{~m}$ diameter in our case. For the optimal footprint size, AGB was estimated with a precision of $2.9 \mathrm{Mg}$ per hectare ( $2.9 \%$ of the average). The results also showed that variance estimates increased constantly with increasing geolocation error. For a geolocation error of $14 \mathrm{~m}$, variance estimates increased by $17 \%$, which justifies investing additional efforts in minimizing it.
\end{abstract}

Keywords: satellite LiDAR; biomass; large-footprint; waveform stacking; forest inventory; model-assisted estimation, hybrid inference

\section{Introduction}

Space-borne LiDAR (Light Detection and Ranging) systems dedicated for estimation of vegetation are expected and needed in the future. Such systems will regularly provide samples of vegetation height information for all parts of the globe, and offer opportunities for estimation of aboveground biomass (AGB) and related variables over large areas.

The Geoscience Laser Altimeter System (GLAS) on board of the Ice, Cloud, and Land Elevation Satellite (ICESat) collected unprecedented global data on threedimensional (3D) forest canopy structure during its mis- sion from 2003 to 2007. It exploited the LiDAR principle, i.e. transmitting a laser pulse and recording of its time-delay, to receive 3D data from the Earth's surface. Although not specifically designed for vegetation mapping, ICESat/GLAS measurements have successfully been used for national to global assessments of basic forest stand characteristics, such as canopy height (Lefsky 2010), growing stock volume (Maselli et al. 2014; Nelson et al. 2009), aboveground biomass (Boudreau et al. 2008; Margolis et al. 2015; Nelson et al. 2017), and aboveground carbon (Neigh et al. 2013).

The upcoming missions, ICESat-II and GEDI (the Global Ecosystem Dynamics Investigation), will provide a very dense, near global sampling of canopy heights. The ATLAS instrument on board of the ICESat- 
II satellite will record a certain number of elevation measurements for each footprint using a single photon counting technique. Single pulses of the ATLAS instrument will be split up into six parallel tracks arranged in three pairs with a distance between pairs of $3.3 \mathrm{~km}$. Within beams, the single footprints will be separated by a distance of $0.7 \mathrm{~m}$ and will have a diameter of $14 \mathrm{~m}$ (Abdalati et al. 2010; Gwenzi et al. 2016). The GEDI mission will collect large-footprint waveforms along 10 parallel tracks with a spacing of about $600 \mathrm{~m}$. Within tracks, the waveforms will be recorded every $25 \mathrm{~m}$ over $25 \mathrm{~m}$ large footprints (NASA 2016). ICEsat data has already been used for large-area forest resource assessments (Nelson et al. 2017), and more applications are expected to come with ICEsat-II and GEDI, and there is a large potential to further develop this technology in order to create fully operational and redundant systems that are tailor-made for national and international forest biomass assessments.

The application of space-borne LIDAR (SL) data for forest monitoring typically requires field collected reference data and suitable modelling strategies for predicting field-observed stand characteristics from SL measurements (Nelson et al. 2017). For developing prediction models, a link between field and SL data is required, which can either be done by measuring ground data directly under SL observations (Montesano et al. 2015; Nelson et al. 2009) or by using an additional data source, such as airborne laser scanning (ALS) for an indirect linkage between field and SL data (Margolis et al. 2015; Nelson et al. 2017). From a survey sampling perspective, the SL measurements form a first sample phase, as they do not fully cover the Earth's surface, which introduces a sampling error attached to estimates derived from such data. For the case of directly linking field and SL data, field observations are sub-sampled within the first sample phase and estimation of target variables and their uncertainties can be done using design-based inference with model-assisted estimation (Gregoire et al. 2011) or by using a so called hybrid approach (Ståhl et al. 2016). If field data is not covered by SL data (the indirect case), the uncertainties from two models (e.g. field to ALS and ALS to SL) need to be considered during estimation. In this case the hybrid three-phase estimators developed by Holm et al. (2017) may be applied. More detail on LiDAR sampling for forest applications can be also found in Wulder et al. (2012).

The spatial mismatch between SL data and field plots as well as the plot size itself are expected to have considerable effects on model fit and the accuracy of AGB estimates. These effects were, for example, studied for ALS data by Gobakken and Næsset (2009) and Frazer et al. (2011). Gobakken and Næsset (2009) found that stem volume estimates were already severely affected by geolocation errors of $5 \mathrm{~m}$ and that errors were especially a problem when small field plots were used. Similar conclusions were later drawn by Frazer et al. (2011), further stating that plot size is a critical design parameter in LiDAR studies affecting (1) the precision and accuracy of AGB estimates, (2) the precision and accuracy of LiDAR metrics, and (3) the negative effect of geolocation error. The recommendation from the study was towards the usage of larger plot sizes in comparison to what is common in forest inventories of temperate and boreal zones (see Tomppo et al. 2010 for common plot sizes). The mismatch of the plot size and the size of a remote sensing pixel was studied in Rejou-Mechain et al. (2014) using 30, globally distributed, large field plots (8-15ha).The study, however, assumed remote sensing data which have no measurement errors, i.e. measurements retrieved the exact value of AGB density as measured in the field plots. The analysis showed that a plot size smaller than a remote sensing pixel causes considerable calibration errors, which was explained by large spatial variability in mean AGB density for plot sizes smaller than 0.25 ha.

For large-footprint, space-borne systems studies about the effects of footprint size and positional accuracy are however still few. Pang et al. (2011) studied the effects of footprint size and off-nadir pointing on the precision of canopy height estimates by means of simulation. They concluded that footprints with a diameter between $25 \mathrm{~m}$ and $30 \mathrm{~m}$ would be ideal to level the effects of vegetation height and terrain slope on waveform length. This footprint size corresponds well with what is commonly used for field plot size in forest inventories of temperate and boreal climate and also with the footprint size that will be used by the future GEDI system. Furthermore, this footprint size was also recommended for the laser altimeter planned for DESDynI mission (Hall et al. 2011). However, the study by Pang et al. (2011) does not handle the influence of geolocation error on estimation of forest variables with large-footprint LiDAR sensors. Goncalves et al. (2017) varied the locations of field plots and used Monte Carlo simulations and binomial distribution to estimate the biomass difference due to the introduced spatial mismatch between field plots and GLAS footprints in Amazon forest. Their analysis showed that the plot-footprint overlap should be larger than $75 \%$ (50\%) for primary (secondary) forest to have a geolocation error less than $20 \%$. However, the study by Goncalves et al. (2017) does not handle the influence of the footprint size on estimation of forest variables.

Several studies have used simulated SL data to prepare future space missions. The simulations are usually based either on (1) a radiative transfer model (GastelluEtchegorry et al. 2015; Montesano et al. 2015; North et al. 2010), or (2) on data from airborne sensors (Gwenzi et al. 2016). The radiative transfer model approach requires assumptions on physical geometrical properties of vegetation, whereas the data approach requires corrections for the sensor characteristics affecting the recorded signal. Blair and Hofton (1999) modelled largefootprint LiDAR waveform data using a vertical distribution of intercepted surfaces approximated with data 
from a small-footprint LiDAR system. The returned waveform from the large-footprint system was obtained using a composition of elementary pulses reflected from each element within the large footprint. They modeled the elementary reflections with the spatial intensity properties of a large-footprint system using a normal distribution over finite vertical and horizontal distances and convolved the sum of elementary reflections with a Gaussian approximation of the impulse response of a large-footprint system to obtain "pseudo-waveforms". High correlations were observed when simulated large footprints were compared with data from the airborne large-footprint system "Laser Vegetation Imaging Sensor" (LVIS). They concluded that the simulated waveforms could be useful for pre-launch simulations of upcoming space-borne LiDAR systems. Duong et al. (2009) have shown that ALS can very well explain ICESat waveforms of $70 \mathrm{~m}$ footprint. However, as discrete points were used, the blurring effect of waveforms (ca 5 ns duration) was not found for clearly defined objects (e.g. horizontal ground).

The overall objective of this paper is to study the effect of footprint size and geolocation error on AGB estimates obtained from a first-phase sample of simulated SL footprints and a smaller second-phase sample of coregistered field plots. The method for SL waveform simulation is based on a spatial integration of the interactions of individual laser pulses and the object, i.e. smallfootprint waveforms, found within a large-footprint, SL beam cone. This, so-called waveform stacking, involves range corrections for the flight trajectory and oblique looking. Thus, the primary difference between airborne and space-borne waveforms we consider lies in the footprint size, whereas the length and shape of the airborne system response (emitted pulse recorded by the detector) "define" the length of pulses from simulated spaceborne waveforms. To emphasize that the SL waveforms are simulated, they will be referred here as simulated space-borne LiDAR (SSL) waveforms.

To study the effect of footprint size and geolocation errors on AGB estimates, nadir-looking SSL waveforms with different footprint sizes were simulated for a predefined monitoring strategy. The advantage of studying a real site is the large amount of ground reference data available. From the SSL waveforms, various waveform metrics were derived, which provided the input for the AGB estimation including uncertainty analyses. Based on the outcome of these analyses recommendations were drawn for the design of future SL systems rather than to simulate a particular sensor.

The paper is structured in the following way. First, we present the study site and data used for the simulation of SL waveforms. Second, we describe the methods for SL waveform simulation. Third, metrics for predicting AGB are defined and derived from the SSL waveforms. Fourth, the framework for estimating AGB and its uncertainty is introduced and results are presented and discussed. Finally, conclusions and recommendations with respect to forestry applications are drawn for future SL systems.

\section{Study Site and Data}

\section{Study Site and Forestry Inventory Data}

The test site Remningstorp is located in the south of Sweden (58 $\left.30^{\prime} \mathrm{N}, 13^{\circ} 40^{\prime} \mathrm{E}\right)$. The estate covers about 1,300 ha of managed forest land. Prevailing tree species are Norway spruce (Picea abies), Scots pine (Pinus sylvestris) and birch (Betula spp.). The topography is flat with a ground elevation between 120 and $145 \mathrm{~m}$ above sea level. During summer 2014, 264 field plots with a radius of $10 \mathrm{~m}$ were distributed evenly using a square grid with $200 \mathrm{~m}$ spacing (Figure 1, the filled circles). On these plots, stem diameter at breast height ( $\mathrm{dbh}$ ) and tree species were registered for all trees with $\mathrm{dbh} \geq 40 \mathrm{~mm}$, while tree height was measured for a sample of trees. The coordinates of the plot centers were measured with differential GNSS (Global Navigation Satellite System). In addition to the field data, a manual interpretation of the land use/land cover of the Remningstorp area was available from an experienced photo interpreter. The data was used to limit the analysis to productive forest lands.

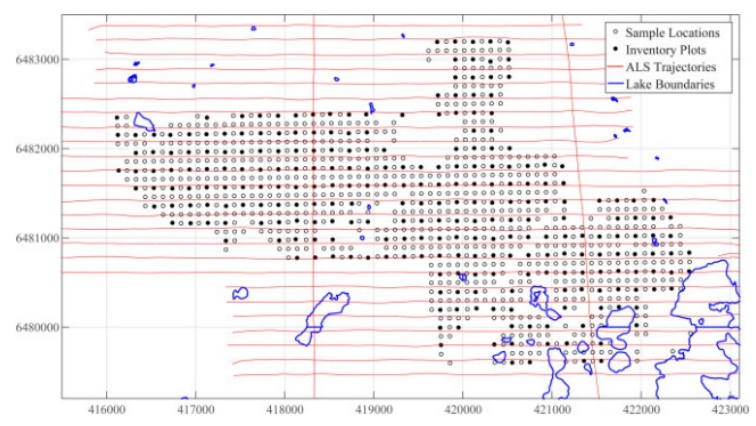

Figure 1: Simulated space-borne LiDAR (SSL) sampling design and inventory strategy employed in the case study for estimating average aboveground biomass in the study area. The open circles together with the closed circles are the firstphase sample of SSL observations, whereas the filled circles only are the second-phase field measurements. The red lines show the strip trajectories of the small-footprint, full-waveform, airborne LiDAR data, used to simulate large-footprint $\mathrm{SL}$ waveforms. The coordinate reference system is SWEREF99 TM.

\section{Airborne Laser Scanning Data}

Full-cover waveform ALS data were available for the entire study area and used for simulating SL waveforms. The data were collected with a RIEGL LMS-Q680i scanner on 14th of September 2014. In total, there were 27 ALS strips covering the forest inventory plots. The majority (25) of the ALS strips were recorded in an eastwest direction and the remaining two in a north-south direction (Figure 1). The east-west strips were separated 
from one another by approximately $150 \mathrm{~m}$, and the average flight height above the terrain was $305 \mathrm{~m}$. As this scanner has a scan angle range of $\pm 30^{\circ}$, the average swath width was $352 \mathrm{~m}$, while the strip overlap was about $55 \%$.

Single ALS strips were collected with mean point densities of last returns ranging between 25 and 28 points per $\mathrm{m} 2$. The footprint diameter at the ground was less than $21 \mathrm{~cm}$ over the whole area, while the average footprint diameter was $15 \mathrm{~cm}$. The scanner was further using a wavelength of $1550 \mathrm{~nm}$ to transmit laser pulses of $5 \mathrm{~ns}$ (the full width at the half maximum of the amplitude). This corresponds to a range resolution of 0.75 $\mathrm{m}$ (Wagner et al. 2006). The RIEGL LSM-Q680i sensor supports multiple time around (MTA) ranging, i.e. it operates with multiple pulses in the air, which then causes range ambiguity for the returns (Rieger and Ullrich 2011). Practically, this means that the scanner does not operate with a single pulse repetition rate (PRR), but changes the PRR constantly among a preset mean PRR. For our data, the mean PRR was set to $360 \mathrm{kHz}$, while the highest and lowest PRR were set to $374 \mathrm{kHz}$ and 348 $\mathrm{kHz}$, respectively. These PRRs caused the range ambiguities of $401 \mathrm{~m}$ and $431 \mathrm{~m}$, respectively. The maximum range of our ALS data was $433 \mathrm{~m}$. This means that there were at maximum two pulses at the same time in the air, i.e. two MTA zones for our data set.

The ALS data were further processed, return-wise, in the sensor's manufacturer software to derive individual returns, and subsequently, a digital terrain model (DTM). There were up to 10 discrete returns per transmitted pulse after the processing. The returns were filtered using the algorithm suggested by Axelsson (1999), resulting in a $1 \mathrm{~m}$ grid DTM of the study area. The DTM as well as the georeferenced returns were projected to the SWEREF99 TM coordinate system.

\section{Methodology}

The methodology includes three major steps: waveform simulation, calculation of waveform metrics and AGB estimation.

We employed a two-phase sampling strategy for AGB estimation, where the first phase includes a systematic sample of 1010 satellite plots with simulated waveform data, while the second-phase sample includes a systematic sub-sample of 264 field plots. The initial SSL sampling grid contained also plots over arable land and other non-forest land-use categories (e.g. lakes); such plots were consequently excluded from the analysis. For the field plots, both inventory and simulated waveform data were available. The systematic sampling was designed in the following way: satellite orbits are assumed to run in a north-south direction and have a spacing of $100 \mathrm{~m}$. Within orbits, every $100 \mathrm{~m}$ an observation was made, so that each field plot is covered with SSL data. Additionally, there are SSL observations inbetween field observations (Figure 1).
For the second-phase sample (the field plots), a direct link between field data and waveform metrics was established. Such an inventory strategy has been used in connection with ICESat-I data, where waveforms were searched in the field for collecting ground reference data (Montesano et al. 2015; Nelson et al. 2009). SL is considered a large-area sampling tool in forest surveys, operating at continental to global scale. In our study, we mimic the implementation of one possible inventory strategy for a much smaller geographic region due to limited availability of data for waveform simulations and restrictions concerning computation time. The focus is on the influence of varying footprint size and geolocation error of SSL waveforms on final AGB estimates.

\section{Waveform Simulation}

The simulation of SL waveforms was done by stacking individually recorded airborne LiDAR waveforms that were located within a larger footprint. The objective was to simulate nadir-looking waveforms whose large footprints are centered at the middle points of the SSL sample plots and the field plots, respectively. In total, 1010 SL large-footprint waveforms were simulated at the corresponding sample locations.

Several processing steps are required to go from raw small-footprint airborne LiDAR waveforms to largefootprint SSL waveforms. The processing involves assigning the MTA zone to recording blocks, waveform geo-referencing, selection of waveforms within the sample plots, range corrections and stacking. This subsection starts by presenting the structure and properties of the raw waveform data, and then, follows the mentioned processing steps. The subsection ends by presenting the metrics derived from the stacked waveforms, which will be used for AGB estimation.

\section{LiDAR Waveforms and Recording Blocks}

The RIEGL LMS-Q680i LiDAR sensor recorded the amplitude of the backscattered energy from a transmitted laser pulse at every nanosecond. This waveform sampling frequency corresponds to a range of $15 \mathrm{~cm}$, i.e. a double way distance of $30 \mathrm{~cm}$. The amplitudes collected over a short period (usually $80 \mathrm{~ns}$, or $160 \mathrm{~ns}$, corresponding to $24 \mathrm{~m}$ and $48 \mathrm{~m}$, respectively) forms a signal, i.e. a waveform, which is then stored by the system in recording blocks (Riegl 2013). The recording blocks are grouped by corresponding preceding laser pulses and are assigned with auxiliary waveform information. This means that several recording blocks can be stored under a single transmitted pulse.

The raw LiDAR waveform data were stored stripwise, and individual recording blocks, as well as their auxiliary information, were accessed by a waveform extraction library (the RiWaveLib) provided by the manufacturer. 
Assigning Recording Blocks to Corresponding Laser Pulses

The used LiDAR sensor utilizes MTA ranging, which requires resolving the range ambiguities of the recording blocks. Methods for resolving the MTA range ambiguities are suggested for the return-wise data processing by Rieger and Ullrich (2011) and Lu et al. (2015). We borrowed the idea of using a DTM for this task, but had to extend the method to raw LiDAR waveforms.

The range ambiguities occurred when new laser pulses were transmitted before the sample block of the preceding pulse was recorded. This practically means that a specific sample block did not necessarily correspond to the preceding laser pulse. In such a case, the sample block had to be assigned to another, earlier laser pulse. As our LiDAR data had at maximum two pulses in the air at the same time (Section 2.2), there were just two possibilities: a recording block had to be related either to the preceding pulse, or to the one before the preceding, pulse.

The range ambiguities of our recording blocks were resolved in the following manner. First, the maximum amplitude return was extracted from each sample block. Then they were assigned with the range relative to their preceding laser pulses. Combing these ranges with the unit beam vectors, a point cloud in the scanner coordinate system was derived. This point cloud was then transformed by direct geo-referencing to a world coordinate system, in our case SWEREF99 TM. Finally, the georeferenced heights of the maximum-amplitude returns were compared with the DTM (Section 2.2).

As expected, the return heights clustered into two groups: one close to the terrain, i.e. in MTA zone 2, and another one erroneously ( $>200 \mathrm{~m}$ ) away from the terrain (closer to the flight trajectory), i.e. in MTA zone 1.

The maximum amplitude returns close to the terrain have the correct range, and thus, their recording blocks are related to the preceding pulse. On the other hand, the remaining returns apparently have an erroneous range. The above procedure was repeated for the ranges derived relative to the one before the preceding pulse. Finally, the points close to the terrain (in MTA zone 2) from both version of ranges were combined into a single, georeferenced point cloud with correctly assigned ranges. This point cloud was also assigned with sample block identifiers as well as the auxiliary data (e.g. amplification settings, recording times of the recording blocks, and unit laser beam vectors in both sensor and world coordinate system, etc.). Such a geo-referenced, maximum-amplitude point cloud was derived for each strip.

\section{Selection of Recording Blocks for Waveform Stacking}

To select all recording blocks for a SSL sample location, the nearest LiDAR strip was first identified using the strips' trajectories, i.e. finding a strip trajectory, which is the closest (in the $x-y$ plane) to the sample location. The selection of the recording blocks near to the sample location was based on the geo-referenced maximumamplitude point cloud (Section 3.1.2). All the recording blocks with maximum-amplitude returns that were located inside a circular neighborhood centered at the sample location were selected. The radius of this circular neighborhood was treated as a variable in a later stage, when different footprint sizes were simulated. The selected maximum-amplitude returns contained also the recording indices of the corresponding recording blocks and their laser pulses, which was then used to access the waveforms. Two different channels were used for the recording blocks: (a) the so-called high power (low amplification) channel, and (b) low power (high amplification) channel. Here, only the recording blocks recorded by the high-power channel were considered for stacking.

\section{Range Corrections}

During the scanning, the absolute position and orientation of the scanner constantly changed, which is described by the flight trajectory. On the other hand, the ranges, i.e. the x-axes of the recording blocks (waveforms), are always defined relative to the instantaneous scanner location. This means that the recording blocks are misaligned when compared according to their original ranges. Therefore, range corrections for the scanner position and orientation are to be applied before the stacking of the recording blocks. The range correction for the scanner position, i.e. the range offset, was derived with respect to a reference point $T_{0}$, set to define the origin of the corrected ranges. The range correction for the scanner orientation was derived with respect to the vertical, as the objective was to simulate the nadirlooking waveforms.

For a sample block $i$ selected for the stacking at the sample location $j$, the corrected range $R_{i}{ }^{\prime}$ was calculated as:

$$
R_{i}^{\prime}=R_{i} \cos \alpha_{i}+\Delta R_{i}
$$

where $R_{i}$ is the original range, $\alpha i$ is the nadir angle of the laser beam vector and $\Delta \mathrm{R}_{i}$ is the range offset. The first term $R_{i} \cos \alpha_{i}$ is the range correction term for the orientation of the scanner. Figure 2 shows schematically the corresponding geometry as well as the range corrections for a particular location and a sample block. The point $T_{i}$ represents an instantaneous position of the scanner, while the vector $\vec{T}_{1} P_{1}$ represents the laser beam vector. The figure also shows a reference point $T_{0}$ which was defined as the mean (of the coordinates) of the trajectory points corresponding to the GPS times of all the recording blocks selected for the stacking. The range offset $\Delta \mathrm{R}_{i}$ was calculated as the magnitude of the vector $\overrightarrow{\mathrm{T}_{\mathrm{o}} T_{l}}$ projected to the unit nadir vector $(\vec{n}=-\vec{k}): \Delta R_{i}=$ $\left\|\overrightarrow{\mathrm{T}_{\mathrm{o}} \mathrm{T}_{1}} \cdot \vec{n}\right\|$. 


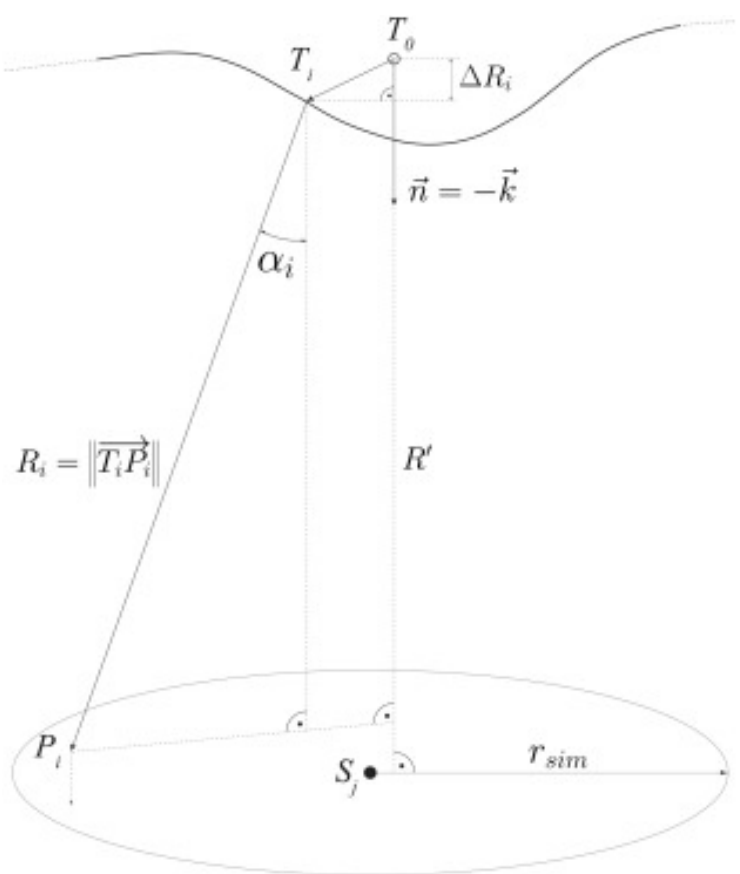

Figure 2: Scanning geometry and the range corrections shown schematically for a particular sample location $\mathrm{S}_{\mathrm{j}}$, and the recording block $\mathrm{i}$. The point $T_{0}$ is the reference point introduced for the range correction, whereas the point $T_{i}$ is the position of the scanner at the trajectory during the recording of the block i. The point $P_{i}$ shows the geolocation of an instantaneous amplitude sample within the recording block i, whereas $R_{i}$ is its range. $\alpha_{i}$ is the nadir angle of the laser beam vector for the block $i$.

The nadir angle $\alpha_{i}$ depends on the plot size (the simulation radius $r_{\text {sim }}$ ) as well as the planar displacement between $S_{j}$ and $T_{0}$ (the nadir angle of the vector $\overrightarrow{\mathrm{T}_{0} S_{1}}$. For $98 \%$ of the SSL sample locations $S_{j}$, the nadir angle of the vector $\overrightarrow{\mathrm{T}_{0} S_{\mathrm{J}}}$ was below $2^{\circ}$, whereas the maximum nadir angle was $14^{\circ}$ for all $S_{j}$. This corresponds to the range corrections of $0.1 \%$ and $3 \%$, respectively.

\section{Recording Blocks Aggregation (Stacking)}

Instantaneous amplitudes of the selected recording blocks were aggregated according to their corrected ranges. A $15 \mathrm{~cm}$ binning of the nadir axis from the reference point $T_{0}$ was introduced, and amplitudes with ranges falling in particular bins were accumulated. Amplitudes smaller than a noise threshold were not considered. Here, the noise threshold of $15 \mathrm{DN}$ was applied, which corresponds to the maximum amplitude among the records at the end of unimodal recording blocks.

For each sample location, an aggregated waveform was derived. The aggregated waveforms were normalized by the number of the selected recording blocks at the particular sample location. This resulted into a mean, nadir-looking, large-footprint waveform per sample location. These simulated waveforms were used for the further analysis.

\section{Waveform Metrics and Simulated Waveform Sets}

\section{Waveform Metrics}

The most common waveform metrics used in previous biomass studies are those considering the vertical distribution of the waveform's energy (e.g., Duong et al. 2009; Lefsky et al. 1999; Popescu et al. 2011; Sun et al. 2008). Typical examples are canopy heights that correspond to certain energy quantiles. Before deriving such waveform metrics, the start- and end of individual waveforms have to be defined. These two waveform features refer to the canopy top and the ground, respectively. For the simulated nadir waveforms the range difference between the canopy top and the ground is the canopy height. The waveform start was defined as the range bin where the mean waveform amplitude exceeded zero for the first time, i.e. the raw amplitude exceeded the noise threshold. The waveform end was defined as the range bin corresponding to $99 \%$ of the waveform area (energy), integrated from the waveform start, i.e. the canopy top. The $99 \%$ quantile was used instead of the hard noise threshold because it showed to be less sensitive to trailing noise, which appears just after the last terrain amplitudes. The energy metrics derived here included three canopy heights. First, the total canopy height $\left(h_{100}\right)$ calculated as the distance between the start and end of the waveform. Second, the height of median energy ( $\left.h_{\mathrm{HOME}}\right)$ calculated as the distance from the waveform end to the bin where $50 \%$ of the waveform area occurs. Third, the canopy height $\left(h_{95}\right)$ calculated similarly as the HOME, but at $95 \%$ of the waveform energy (integrated from the waveform end).

In addition to the energy metrics, a peak analysis was performed to derive peak metrics. The waveform peaks were identified using the findpeaks function in the Signal Processing Tool Box of the Matlab R2016b software (MATLAB 2016). The peak metrics derived here included three parameters. The first peak parameter is a peak-to-peak distance $\left(d_{\mathrm{p} 2 \mathrm{p}}\right)$. For bimodal waveforms, i.e. waveforms with two peaks, $d_{\mathrm{p} 2 \mathrm{p}}$ is uniquely defined. However, for multimodal waveforms ( $>$ more than two peaks), $d_{p 2 p}$ was calculated as the distance from the first to the last peak. For unimodal peaks, i.e. (a single peak detected), $d_{\mathrm{p} 2 \mathrm{p}}$ was replaced with the full waveform width at half of the peak magnitude (FWHM). The remaining two peak parameters are: (i) the amplitude of the last peak $\left(a_{\text {last }}\right)$, and (ii) the full width at half of the last-peak magnitude $\left(d_{\mathrm{FWHM}}\right)$.

The values of the six waveform parameters were derived for all SSL plots in the first sample phase, and were used for regression analyses for assessing AGB.

\section{Waveform sets}

The impacts of footprint size and geolocation error were analyzed independently and with different waveform sets. To analyze the impact of footprint size on biomass 
estimates and their corresponding variance estimates, eight waveform sets were generated using different search radius values (Section 3.1.3). Each set contained 1010 SSL waveforms. The radius values ranged from $2.5 \mathrm{~m}$ to $20 \mathrm{~m}$, with increments of $2.5 \mathrm{~m}$, mimicing different footprint sizes. These eight waveform sets, represented by their waveform metrics, were used as input for the biomass model to derive the footprint size that minimizes the biomass variance estimates.

To analyze the impact of geolocation error on variance estimates, a single waveform set was generated using the footprint size that minimized the biomass variance estimates. This set contained 1010 SSL waveforms as before, and additionally 24 SSL waveforms around each sample location to simulate geolocation errors. This resulted in 25250 SSL waveforms in total. The locations of the 24 additional SSL waveforms were distributed systematically, using a $5 \times 5$ nodes grid, around each sample location. The node spacing was set to $5 \mathrm{~m}$, while the grid sides were parallel to the $\mathrm{x}$ - and $\mathrm{y}$-axis of the world coordinate system. This provided geolocation errors of up to $\pm 10 \mathrm{~m}$ along the $\mathrm{x}$ - and $\mathrm{y}$-axis, and up to \pm 14 . $1 \mathrm{~m}$ along the main diagonal. Figure 3 shows several SSL sample locations and the corresponding grids of 24 additional locations used for analyzing the impact of the geolocation error.

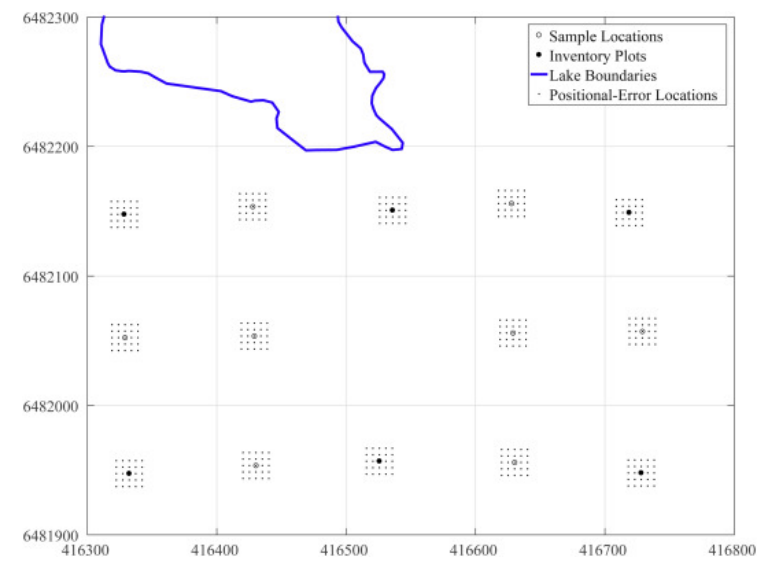

Figure 3: A zoomed-in view into the SSL sample locations and the inventory plots. The smaller grey dots around the SSL sample locations are the additional sample locations introduced to assess the impact of geolocation error. The dots form local grids with a grid spacing of $5 \mathrm{~m}$. Note that the SSL sample locations also includes the Inventory plot locations.

\section{Case study: Application of space-borne LiDAR data in forest surveys}

The 33 waveform sets ( 8 for the footprint simulation and 25 for the geolocation error simulation) were combined with the systematic sample of $n_{I I}=264$ field plots to estimate the biomass of our study area. We employed a two-phase design, where the first phase is a systematic sample of $n_{I}=1010$ single-waveform satellite plots. The second-phase sample includes the 264 field plots, for which a direct link between field data and waveform metrics was established. For the second-phase sample (field plots), we have a full set of information; i.e. AGB was predicted from field measurements using the models from Marklund (1988) and SSL metrics were available from the waveform simulation. For the remaining first-phase sample plots we have only SSL metrics available and AGB was predicted using a model that was developed from the ground reference data.

The model had the following form: $y_{i}=\beta_{0}+\beta_{1} d_{\mathrm{p} 2 \mathrm{p}}+\beta_{2} h_{\mathrm{HOME}}+\beta_{3} h_{95}+\epsilon_{i}$, and parameter values were estimated using the generalized least squares technique (McCulloch et al. 2008) as implemented in the nlme R- package (Pinheiro et al. 2016). To avoid backtransformation bias and to tackle heteroscedasticity, residual variance was modeled as a function of the $h_{\mathrm{HOME}}$ predictor variable. The chosen model was selected from all possible linear models, not considering interaction terms, that could be built with our six waveform metrics (in total 63 possible combinations). The models were fit to the waveform set that had no geolocation error and a footprint size that corresponded to the size of the field plots (10 m radius). As selection criteria, Bayes information criterion and residual standard error were used.

The selected model was then fit to all 32 waveform sets individually, and model fits were evaluated using model efficiency $(M E)$ and root mean square error (RMSE), where

$$
\begin{aligned}
& M E=1-\frac{S_{\text {res }}}{{S S_{\text {mean }}}} \\
& R M S E=\sqrt{\frac{S S_{\text {res }}}{n_{11}-n_{\text {var }}}}
\end{aligned}
$$

with $S S_{\text {res }}=\sum_{i=1}^{n_{I I}}\left(y_{i}-\widehat{y_{l}}\right)^{2}$ and $S S_{\text {res }}=\sum_{i=1}^{n_{I I}}\left(y_{i}-\right.$ $\left.\bar{y}_{i}\right)^{2}$ denoting the number of model parameters. To further check if models were correctly specified, graphs of observed AGB plotted against model predictions were constructed in two ways: (1) original pairs of observations and predictions and (2) group means of observed and predicted values. For the latter pairs of observations and predictions $\left(y_{i}, \widehat{y}_{l}\right)$ were ordered with respect to $\widehat{y}_{l}$ and then grouped into categories of ten observations. For each category, averages of observed and predicted AGB were calculated and plotted against each other. For correctly specified models, points should follow the 1:1 line with intercept 0 and slope 1, e.g. McRoberts et al. (2013). Graphs for the footprint waveform sets are provided in Appendix A, and for the geolocation waveform sets, graphs are provided in Appendix B.

For estimating average biomass density $\bar{y}$ of the study area and its variance, two inferential frameworks were applied: (1) model-assisted estimation under design-based inference and (2) hybrid inference combining the inferential frameworks model-based and designbased (Ståhl et al. 2016). The two-phase sampling model-assisted estimator for $\bar{y}$ is (Mandallaz 2008, p80)

$$
\hat{\bar{y}}_{m a}=\frac{1}{n_{l}} \sum_{k \in S_{l}} \hat{y}_{k}+\frac{1}{n_{l l}} \sum_{k \in S_{l l}} \hat{e}_{k}
$$


where $\hat{y}_{k}$ is AGB in Mg per hectare of population element $k$ predicted from the regression model, and $\hat{e}_{k}$ is the model residual $\hat{e}_{k}=y_{k}-\hat{y}_{k}$. A variance estimator for $\hat{\bar{y}}_{m a}$ is (Mandallaz 2008, p81)

$\left.\widehat{V(} \hat{\bar{y}}_{m a}\right)=\left(1-\frac{n_{l l}}{n_{l}}\right) \frac{\sum_{k \in S_{l l}}\left(\hat{e}_{k}-\frac{\sum_{k \in S_{l}} \hat{e}_{k}}{n_{l l}}\right)}{\left(n_{l l}\left(n_{l l}-1\right)\right)}+\frac{\sum_{k \in S_{l l}}\left(\hat{y}_{k}-\frac{\sum_{k \in S_{l l} y_{k}}}{n_{l l}}\right)}{\left(n_{l}\left(n_{l l}-1\right)\right)}$

Under hybrid inference, $\bar{y}$ is estimated using the following estimator (Ståhl et al. 2016):

$$
\hat{\bar{y}}_{h y}=\frac{1}{n_{l}} \sum_{i \in S_{l}} \hat{y}_{k}
$$

Under sampling designs that use equal inclusion probabilities, as in our case, and for models for which $\sum \hat{e}_{k}$ is zero, the two estimators from Eq. (4) and Eq. (6) will yield identical results (e.g., Magnussen 2015).

For the variance of $\hat{\bar{y}}_{h y}$ we have a design-based component from the sample nature of satellite observations and a model-based component, since AGB for phaseone units without field data was predicted using a model. Although, systematic sampling is the widely accepted standard in surveys of natural resources, it has the drawback that no unbiased variance estimator exist due the fact that many second-order inclusion probabilities are zero. The most common strategy is to treat sampling units as they were selected randomly and to apply the according variance estimator for simple random sampling. This approach will yield conservative estimates that overestimate the variance of the total estimator (e.g., Ene et al. 2013); the degree of overestimation is unknown. In our case this is not relevant, since the design-based variance component is fixed (the sampling design does not change) and our focus is on the modelbased variance component, which is influenced by footprint size and geolocation error. A variance estimator is

$$
\widehat{V}\left(\hat{\bar{y}}_{h y}\right)=\widehat{V}_{d b}+\widehat{V}_{m b}
$$

where $\widehat{V}_{d b}=\frac{1}{n_{l}} \sum_{S_{l}} \frac{\left(\hat{y}_{k}-\hat{\bar{y}}\right)^{2}}{n_{l}-1}$ is the simple random sampling without replacement estimator for the designbased component of total variance, and $\widehat{V}_{m b}=\frac{1}{n_{l}} \hat{\sigma}_{e}^{2}+$ $\boldsymbol{v}^{\prime} \boldsymbol{X} \widehat{\operatorname{cov}}(\widehat{\boldsymbol{\beta}}) \boldsymbol{X}^{\prime} \boldsymbol{v}$ is the respective model-based component (Magnussen et al. 2016, Eq. 6), where. Here, $\boldsymbol{X}$ is the design matrix of the model with dimensions $n_{I} \times p+1$, where $p$ is the number of predictors, is a $n_{I} \times 1$ matrix of entries with the value $1 / n_{l}$, and $\hat{\sigma}_{e}^{2}$ is the estimated residual variance calculated as $\hat{\sigma}_{e}^{2}=\sum_{s_{l l}} w_{i}^{2} e_{i}^{2} /$ $\left(n_{l l}-n_{\text {var }}\right)$. The weights $w_{i}$ are used in the generalized least squares regression to account for heteroscedasticity and are derived from the residual variance model. Note that for large-area (national to global) surveys, $\hat{\sigma}_{e}^{2}$ is small compared to the second term in $\widehat{V}_{m b}$ and can be ignored (Ståhl et al. 2016). For a more intuitive interpretation of results, variance estimates are transformed to standard error estimates by taking the square root $\widehat{S E}=\sqrt{ } \hat{V}(\hat{\bar{y}})$.

\section{Results and Discussion}

\section{Simulated Waveforms and Selection of Waveform Metrics}

Figure 4 shows nadir-looking waveforms stacked using the radius of $10 \mathrm{~m}$ centered at four different field plot locations. Additionally, the figure shows corresponding georeferenced ALS returns, plotted in the x-z plane. The coordinates are given relative to the field plot center. The $z_{S j}$ coordinate of a field plot center $S_{j}$ was derived from the LiDAR DTM. The waveform's range is plotted vertically, while the mean amplitude of the stacked waveform is plotted horizontally. As the waveforms have nadir-looking geometry, the range is also expressed as the relative height (shown on the left vertical axis) used to plot the returns. The relative height for a nadir range $R_{i}{ }^{\prime}$ was calculated as: $Z_{T 0}-R_{i}{ }^{\prime}-Z_{S j}$ (see Figure 2 ). Note the different limits of the vertical axis for the four subfigures.
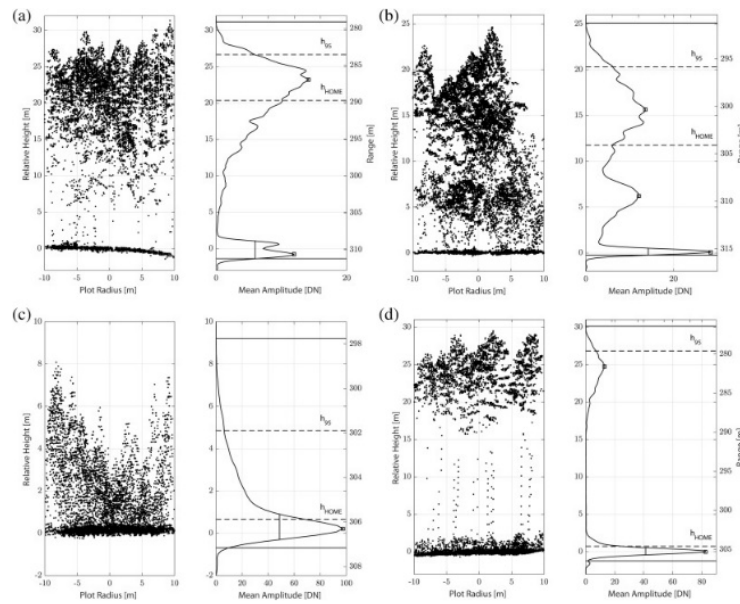

Figure 4: Examples of SSL waveforms stacked using the radius of $10 \mathrm{~m}$ for four different field plots. The start and end of the waveforms are shown by upper and lower, solid horizontal lines, respectively. The dashed horizontal lines show $h_{H O M E}$ and $h_{95}$ levels. The detected peaks are marked by the black squares, whereas $d_{F W H M}$ of the last peak is shown by the vertical line. Note that the limits of the waveform amplitude axis are different for each subfigure, but the axis is always split in the increments of $20 \mathrm{DN}$ to make relative comparison easier.

As shown by Figure 4, the stacked waveforms reflect different vegetation structure well. Figure 4 a shows a typical two-layer plot with high vegetation and the corresponding bi-modal waveform. This plot is also slightly sloped, which resulted in a broader ground part of the waveform. It can also be seen that the peak detection algorithm is robust, as the sub-dominant ground peak was omitted. Figure $4 \mathrm{~b}$ shows a plot with high vegetation and understory that resulted in a multimodal waveform with three peaks identified. For this waveform, the ground part is much narrower as the terrain is flat within the plot. Finally, Figure $4 \mathrm{c}$ shows a plot with dense low vegetation, which resulted in a unimodal 
waveform where the ground and vegetation part are mixed.

Figure 4 also shows that the waveform metrics are robust for each of the three waveform types. The $99 \%$ energy quantile used to define the waveform end successfully filtered out the trailing noise of the waveform in Figure 4d. For the rest of the examples, the $99 \%$ quantile was found just slightly inside the ground part, but is still enough robust to define the end of the waveform well. The $h_{100}, h_{95}$ and $h_{\text {HOME }}$ metrics reflect the canopy height well, and, as shown later in Figure 5, have very high correlation $(>0.7)$ with the field AGB. Only in Figure $4 d, h_{\mathrm{HOME}}$ is very close to the ground, erroneously suggesting low AGB within the plot. This plot was select as the one that is far away from the main trend in the scatter plot of $h_{\mathrm{HOME}}$ and AGB values (Figure 5). For comparison, the plot in Figure 4a (also a bimodal waveform), is placed close to the main trend and has similar field AGB. The reason for small $h_{\mathrm{HOME}}$ in Figure $4 \mathrm{~d}$ is a large amplitude of the ground peak, which makes the median energy less sensitive to the vegetation height and more close to the ground. Nevertheless, Figure 5 shows that erroneous $h_{\mathrm{HOME}}$ values appeared just for a few plots, while the majority of the plots showed a high correlation (0.84) with field-observed AGB.

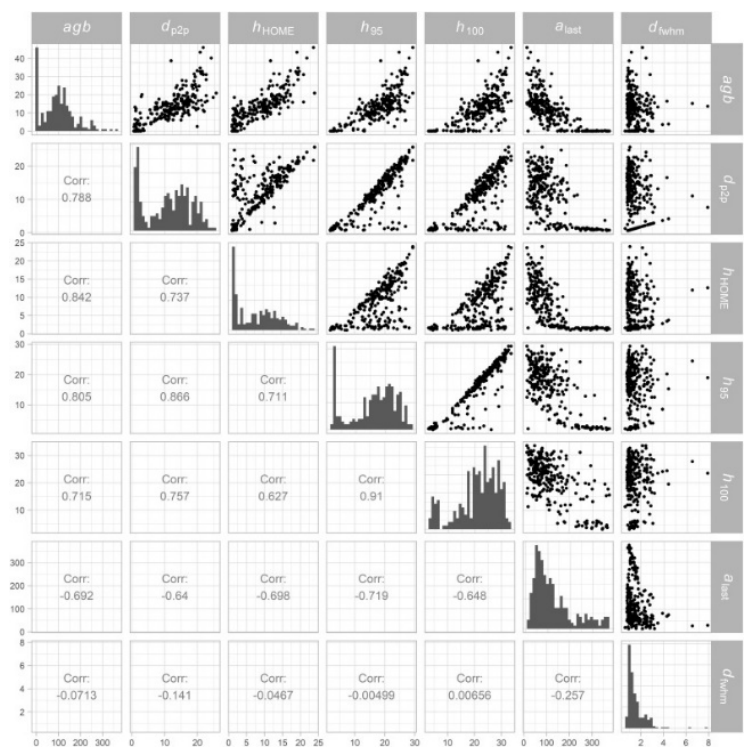

Figure 5: Scatterplot matrix of waveform metrics and fieldobserved AGB.

Figure 5 shows a scatter plot matrix for AGB and all waveform metrics. The metrics were derived from the $10 \mathrm{~m}$ radius waveforms for all of the 264 field plots. In the scatter plot matrix, Pearson's correlation coefficient of variable pairs is reported below the main diagonal, while on the main diagonal, the distributions of variable values are provided in the form of histograms. Table 1 summarizes the statistics of the three predictors used for AGB prediction by sample phase. There is a small difference in the mean values between only-field and only- satellite waveform metrics, where the metrics from the field-sample were slightly smaller.

Table 1: Summary statistics of predictor variables used in the biomass estimation model, separated by sampling phases: $c v$ -coefficient of variation, skew - skewness, kurt-kurtosis.

The footprint radius for feature extraction was $10 \mathrm{~m}$.

\begin{tabular}{|c|c|c|c|c|c|c|c|c|}
\hline & $\mathrm{n}$ & & $\begin{array}{l}\mathrm{Mi} \\
\mathrm{n}\end{array}$ & $\begin{array}{l}\mathrm{Ma} \\
\mathrm{x}\end{array}$ & $\begin{array}{l}\text { Mea } \\
\mathrm{n}\end{array}$ & $\mathrm{cv}$ & $\begin{array}{l}\text { ske } \\
\text { w }\end{array}$ & $\begin{array}{l}\text { kur } \\
\mathrm{t}\end{array}$ \\
\hline \multirow[t]{3}{*}{$\begin{array}{l}\text { Fiel } \\
\text { d }\end{array}$} & 264 & $\mathrm{~d}_{\mathrm{p} 2 \mathrm{p}}$ & 0.9 & $\begin{array}{l}25 . \\
5\end{array}$ & 11.1 & $\begin{array}{l}0.6 \\
2\end{array}$ & $\begin{array}{l}- \\
0.1 \\
1\end{array}$ & $\begin{array}{l}- \\
1.2 \\
3\end{array}$ \\
\hline & & $\begin{array}{l}\mathrm{h}_{\mathrm{HO}} \\
\mathrm{ME}\end{array}$ & 1.2 & $\begin{array}{l}23 . \\
7\end{array}$ & 8.1 & $\begin{array}{l}0.7 \\
1\end{array}$ & $\begin{array}{l}0.4 \\
4\end{array}$ & $\begin{array}{l}- \\
0.9 \\
2\end{array}$ \\
\hline & & $\mathrm{h}_{95}$ & 2.1 & $\begin{array}{l}29 . \\
1\end{array}$ & 16.1 & $\begin{array}{l}0.4 \\
7\end{array}$ & $\begin{array}{l}- \\
0.5 \\
3\end{array}$ & $\begin{array}{l}- \\
0.8 \\
5\end{array}$ \\
\hline \multirow[t]{3}{*}{$\begin{array}{l}\text { Sat } \\
\text { el- } \\
\text { lite }\end{array}$} & 746 & $\mathrm{~d}_{\mathrm{p} 2 \mathrm{p}}$ & 0.9 & $\begin{array}{l}30 . \\
0\end{array}$ & 11.5 & $\begin{array}{l}0.6 \\
2\end{array}$ & $\begin{array}{l}- \\
0.0 \\
3\end{array}$ & $\begin{array}{l}- \\
1.1 \\
3\end{array}$ \\
\hline & & $\begin{array}{l}\mathrm{h}_{\mathrm{HO}} \\
\mathrm{ME}\end{array}$ & 0.9 & $\begin{array}{l}24 . \\
3\end{array}$ & 8.3 & $\begin{array}{l}0.7 \\
2\end{array}$ & $\begin{array}{l}0.4 \\
3\end{array}$ & $\begin{array}{l}- \\
1.0 \\
6\end{array}$ \\
\hline & & $\mathrm{h}_{95}$ & 1.8 & $\begin{array}{l}33 . \\
0\end{array}$ & 17.3 & $\begin{array}{l}0.4 \\
3\end{array}$ & $\begin{array}{l}- \\
0.5 \\
4\end{array}$ & $\begin{array}{l}- \\
0.5 \\
8\end{array}$ \\
\hline \multirow[t]{3}{*}{ All } & $\begin{array}{l}101 \\
0\end{array}$ & $d_{p 2 p}$ & 0.9 & $\begin{array}{l}30 . \\
0\end{array}$ & 11.4 & $\begin{array}{l}0.6 \\
2\end{array}$ & $\begin{array}{l}- \\
0.0 \\
5\end{array}$ & $\begin{array}{l}- \\
1.1 \\
4\end{array}$ \\
\hline & & $\begin{array}{l}\mathrm{h}_{\mathrm{HO}} \\
\mathrm{ME}\end{array}$ & 0.9 & $\begin{array}{l}24 . \\
3\end{array}$ & 8.3 & $\begin{array}{l}0.7 \\
1\end{array}$ & $\begin{array}{l}0.4 \\
3\end{array}$ & $\begin{array}{l}- \\
1.0 \\
2\end{array}$ \\
\hline & & $\mathrm{h}_{95}$ & 1.8 & $\begin{array}{l}33 . \\
0\end{array}$ & 17.0 & $\begin{array}{l}0.4 \\
4\end{array}$ & $\begin{array}{l}- \\
0.5 \\
5\end{array}$ & $\begin{array}{l}- \\
0.6 \\
3\end{array}$ \\
\hline
\end{tabular}

\section{Case Study}

By fitting the AGB prediction model to each of the waveform sets and consecutively applying the estimators, we obtained estimates of AGB density and corresponding standard errors. Results are summarized in Table 2 and Table 3. As the difference of AGB estimates from Eq. (4) and Eq. (6) was close to zero (1. $4 \times 10^{-14}$ on average), results are summarized under one column with generic notation $\hat{\bar{y}}$. From Table 2 it is obvious that the best model fits and lowest standard errors were achieved for footprint sizes that are close to the actual field plot size (i.e. from $7.5 \mathrm{~m}$ to $12.5 \mathrm{~m}$ ). Regarding geolocation error (Table 3 ), standard error estimates generally increase with increasing distance of displacement, although substantial variation was observed among waveform sets of common distance but different direction of displacement (Figure 6). The lowest standard error was consequently observed when there was a perfect match between SSL and field data. 
Table 2: Model fit statistics, AGB density estimates and estimated standard errors in dependence of footprint size: $M E-$ model efficiency, RMSE - root mean square error, $\hat{\bar{y}}-$ estimated biomass density, $\widehat{S E}\left(\hat{\bar{y}}_{m a}\right)$ - model-assisted standard error estimate, $\widehat{S E}\left(\hat{\bar{y}}_{\text {hy }}\right)$ - hybrid-inference standard error estimate.

\begin{tabular}{|l|l|l|l|l|l|}
\hline $\begin{array}{l}\text { Foot- } \\
\text { print } \\
\text { ra- } \\
\text { dius[m } \\
]\end{array}$ & ME & $\begin{array}{l}\text { RMS } \\
\mathrm{E} \\
{[\mathrm{Mg}} \\
\left.\mathrm{ha}^{-1}\right]\end{array}$ & $\begin{array}{l}\widehat{\hat{y}} \\
{[\mathrm{Mg}} \\
\left.\mathrm{ha}^{-1}\right]\end{array}$ & $\begin{array}{l}\widehat{S E}\left(\hat{\bar{y}}_{m a}\right) \\
{[\mathrm{Mg}} \\
\left.\mathrm{ha}^{-1}\right]\end{array}$ & $\begin{array}{l}\widehat{S E}\left(\hat{\bar{y}}_{h y}\right) \\
{[\mathrm{Mg}} \\
\left.\mathrm{ha}^{-1}\right]\end{array}$ \\
\hline 2.5 & $\begin{array}{l}0.6 \\
2\end{array}$ & 45.9 & $\begin{array}{l}101 . \\
1\end{array}$ & 3.4 & 4.1 \\
\hline 5.0 & $\begin{array}{l}0.7 \\
1\end{array}$ & 39.6 & $\begin{array}{l}101 . \\
4\end{array}$ & 3.2 & 3.3 \\
\hline 7.5 & $\begin{array}{l}0.7 \\
8\end{array}$ & 35.1 & $\begin{array}{l}101 . \\
9\end{array}$ & 3.0 & 2.9 \\
\hline 10.0 & $\begin{array}{l}0.8 \\
0\end{array}$ & 33.4 & $\begin{array}{l}101 . \\
3\end{array}$ & 2.9 & 2.8 \\
\hline 12.5 & $\begin{array}{l}0.7 \\
8\end{array}$ & 34.6 & $\begin{array}{l}100 . \\
8\end{array}$ & 2.9 & 2.9 \\
\hline 15.0 & $\begin{array}{l}0.7 \\
6\end{array}$ & 36.7 & $\begin{array}{l}100 . \\
6\end{array}$ & 3.0 & 2.9 \\
\hline 17.5 & $\begin{array}{l}0.7 \\
3\end{array}$ & 38.3 & $\begin{array}{l}100 . \\
7\end{array}$ & 3.1 & 3.1 \\
\hline 20.0 & $\begin{array}{l}0.7 \\
1\end{array}$ & 39.8 & $\begin{array}{l}100 . \\
6\end{array}$ & 3.2 & 3.1 \\
\hline & & & & & \\
\hline
\end{tabular}

Table 3: Model fit statistics, AGB density estimates and estimated standard errors in dependence of horizontal displacement distance (the footprint radius was fixed to $10 \mathrm{~m}$ ). Results for different directions of the same displacement are averaged. Abbreviations are as follows: $M E$ - model efficiency, RMSE - root mean square error, $\hat{\bar{y}}$ - estimated biomass density, $\widehat{S E}\left(\hat{\bar{y}}_{m a}\right)-$ model-assisted standard error estimate, $\widehat{S E}\left(\hat{\bar{y}}_{h y}\right)$ - hybrid-inference standard error estimate.

\begin{tabular}{|c|c|c|c|c|c|c|}
\hline $\begin{array}{l}\text { Dis- } \\
\text { place } \\
\text { ment } \\
{[\mathrm{m}]}\end{array}$ & $\begin{array}{l}\mathrm{Nu} \\
\mathrm{mb} \\
\text { er } \\
\text { of } \\
\text { ob- } \\
\text { ser- } \\
\text { va- } \\
\text { tion } \\
\text { s }\end{array}$ & $\begin{array}{l}\text { M } \\
\mathrm{E}\end{array}$ & $\begin{array}{l}\text { RMSE } \\
{[\mathrm{Mg}} \\
\left.\mathrm{ha}^{-1}\right]\end{array}$ & $\begin{array}{l}\hat{\bar{y}} \\
{[\mathrm{M}} \\
\mathrm{g} \\
\mathrm{ha}^{-} \\
\left.{ }^{1}\right]\end{array}$ & $\begin{array}{l}\widehat{S E}\left(\hat{\bar{y}}_{m}\right. \\
{[\mathrm{Mg}} \\
\left.\mathrm{ha}^{-1}\right]\end{array}$ & $\begin{array}{l}\widehat{S E}\left(\hat{\bar{y}}_{h y}\right. \\
{[\mathrm{Mg}} \\
\left.\mathrm{ha}^{-1}\right]\end{array}$ \\
\hline 0.0 & 1 & $\begin{array}{l}0 . \\
80\end{array}$ & 33.4 & $\begin{array}{l}101 \\
.3 \\
\end{array}$ & 2.9 & 2.8 \\
\hline 5.0 & 4 & $\begin{array}{l}0 . \\
75\end{array}$ & 36.9 & $\begin{array}{l}101 \\
.0\end{array}$ & 3.1 & 3.3 \\
\hline 7.1 & 4 & $\begin{array}{l}0 . \\
73\end{array}$ & 38.8 & $\begin{array}{l}100 \\
.0\end{array}$ & 3.1 & 3.5 \\
\hline 10.0 & 4 & $\begin{array}{l}0 . \\
67\end{array}$ & 42.6 & $\begin{array}{l}100 \\
.3\end{array}$ & 3.3 & 3.8 \\
\hline 11.2 & 8 & $\begin{array}{l}0 . \\
65\end{array}$ & 43.6 & $\begin{array}{l}100 \\
.0\end{array}$ & 3.3 & 4.0 \\
\hline 14.1 & 4 & $\begin{array}{l}0 . \\
60\end{array}$ & 47.2 & $\begin{array}{l}100 \\
.5\end{array}$ & 3.5 & 4.4 \\
\hline
\end{tabular}

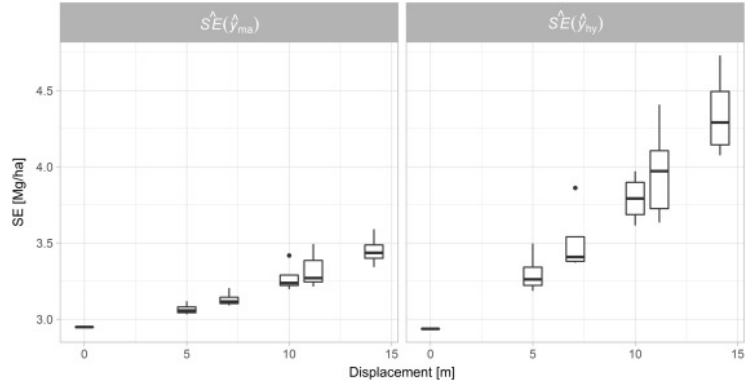

Fig. 6. Estimated standard errors of AGB estimates in dependence of horizontal displacement distance between field and satellite observations (the footprint radius was fixed to 10 $\mathrm{m})$. The left panel gives estimates following the model-assisted estimator and the right panel following hybrid-inference. Differences among observations of the same displacement are due to different directions of displacement.

In both cases, geolocation error and footprint size, variation in standard error estimates are largely explained by changes in model-fit statistics (ME and $R M S E)$ as expected from the estimators. Point $\hat{\bar{y}}$ estimates from either model-assisted estimation or hybrid inference are almost identical as the applied sampling design used equal inclusion probabilities for selecting SL and field data (Magnussen 2015). Interval $\widehat{S E}$ estimates, however, showed some differences between the two inferential frameworks. It appears that, in particular, the hybrid approach for variance estimation is more affected by decreasing model quality due to mismatches in either footprint size or geolocation (Figure 6 for geolocation error). In case of varying footprint size, differences in standard error estimates are only clearly visible for the smallest footprint size of $2.5 \mathrm{~m}$ (Table 2). The other footprint sizes used seemed to be close enough to the actual field plot size, so that the decrease in model quality was not strong enough to lead to a notable difference between the two inferential frameworks.

The hybrid standard error estimates varied, further, also consistently more among the different directions of displacement when the distance was kept constant (Figure 6). The cause for this behavior can be found in the fundamentally different inferential frameworks. While with design-based inference (here with model-assisted estimation), the population is considered to be fixed and randomization enters through the random selection of samples following a predefined probability sampling design, model-based inference assumes that the population is a realization of a random process and that the sample is fixed instead (Magnussen 2015; Ståhl et al. 2016). Uncertainty under the model-based paradigm arises from estimating model parameters and from lackof -fit residuals, while with model-assisted estimation, uncertainty comes from the variation between population parameter estimates from different samples (Magnussen 2015). For the latter case, the quality of the model does typically not affect the approximately unbiasedness of the estimators (Magnussen 2015). In the 
model-based case, however, inference relies on correctly specified models. Regarding the hybrid estimator in our study, we observed that estimates of the designbased component (Eq. 7) were relatively stable across the different conditions tested here, while the modelbased component reacted heavily on changes on the estimated uncertainty of model parameter estimates caused by geolocation error and discrepancies in footprint size. Such a difference between variance estimates from either design-based with model-assisted estimation and model-based inference was also observed by Saarela et al. (2016b) when studying the effect of geolocation errors in a Monte-Carlo simulation study. The differences vanished, however, with increasing sample size. As a note of caution, we would like to mention that our results and conclusions are based on one single sample out of the many possible samples that could be drawn from our population. More detailed conclusions about the behavior of the hybrid variance estimator when model quality decreases due to mismatches between datasets, would require a Monte-Carlo simulation study. Such simulation studies typically require that target and auxiliary variables are available for all population elements. With respect to simulating satellite waveforms, the computational burden was, however, too heavy for the current study.

For point estimates, we further observed some variation among values from the different waveform sets. For example, the lowest AGB density observed in Table 2 is $100.6 \mathrm{Mg}$ per hectare, while the largest value observed is $101.9 \mathrm{Mg}$ per hectare. This variation can be entirely attributed to differences in the simulated waveforms from including different ALS data in the simulations by changing footprint size. This directly affects parameter estimates and thus point and interval estimates of AGB density. In combination with zero model residual sums and equal inclusion probabilities, the model-assisted correction factor in Eq. (4), as already mentioned, has no effect. Note, however, that the individual point estimates lie well within each other's confidence intervals. The same applies to the results in Table 3.

For sake of comparison, the field-based estimate of AGB was 97.1 Mg per hectare with an estimated standard error of $4.6 \mathrm{Mg}$ per hectare. Thus, by including SSL data to facilitate AGB estimation in the manner shown here, the relative standard error of estimation was reduced by approx. $37 \%$ in the best case. The rather small difference of the field-based point estimate in comparison to the SSL supported estimates can be explained by the summary provided in Table 1 . The slightly larger model predictor variables on SSL-only plots resulted in, on average, larger model predictions. Otherwise, the statistics in Table 1 show that the forest conditions in the two sets are comparable.

\section{Conclusions}

In this study we analyzed the effect of simulated LiDAR footprint size and geolocation error on AGB estimates. The AGB estimates were obtained from a first phase sample of simulated SL footprints and a smaller second phase sample of co-registered field plots. The largefootprint, nadir-looking SL waveforms were simulated by spatial integration of the small-footprint ALS waveforms found within the SSL beam cone. The shape of the simulated waveforms reflected well different forest structure, whereas the height metrics derived from the SSL waveforms showed high correlation $(>0.7)$ with the AGB of the field plots.

Simulating space-borne LiDAR waveforms with different footprint size, we showed that the size of field plots should match the footprint size of the satellite observations. The other way around, we could also say that future space-borne LiDAR missions should be planned in a way that footprint sizes match field plot sizes commonly used in forest inventories. The larger the mismatch, the more the modeling efforts are affected in both directions (under or oversized footprints or field plots, respectively).

We saw a clear effect of geolocation error in the sense that standard errors increased with increasing horizontal displacement. The largest standard error estimate was $17 \%$ larger than the smallest standard error estimate if model-assisted estimation was used. For modelbased inference, the estimated difference was $36 \%$. It is, thus, important that future LiDAR satellites designed for operational forest monitoring will provide accurate coordinates, preferably sub meter, for the position of the laser footprints. Since the field data generally will be obtained after the LiDAR data, it is the coordinate for the actual footprint, and not the possibility to beforehand hit a specific target that is of importance. The results in this article is however dependent on the properties of the test site (temperate forest in southern Sweden). In homogenous forest areas such an effect can somewhat be dampened by autocorrelation, meaning that nearby points tend to be similar in the stand characteristics. In fragmented areas (forest, non-forest), however, or intensively managed forest areas (clear cut systems, evenaged plantation forest), correlation lengths can be short and areas in the immediate neighborhood of the field sample location can have completely different properties.

\section{Acknowledgments}

The research leading to these results has received funding from the European Community's Seventh Framework Program ([FP7/2007-2013]) under the Advanced_SAR project (grant agreement no 606971). We thank Björn Nilsson for conducting the manual photo interpretation of the Remningstorp estate that was needed for limiting the analysis to productive forest 
lands. We also thank Andreas Roncat for valuable discussions and clarifications of raw waveform data structure and the waveform extraction library.

\section{Appendix A}

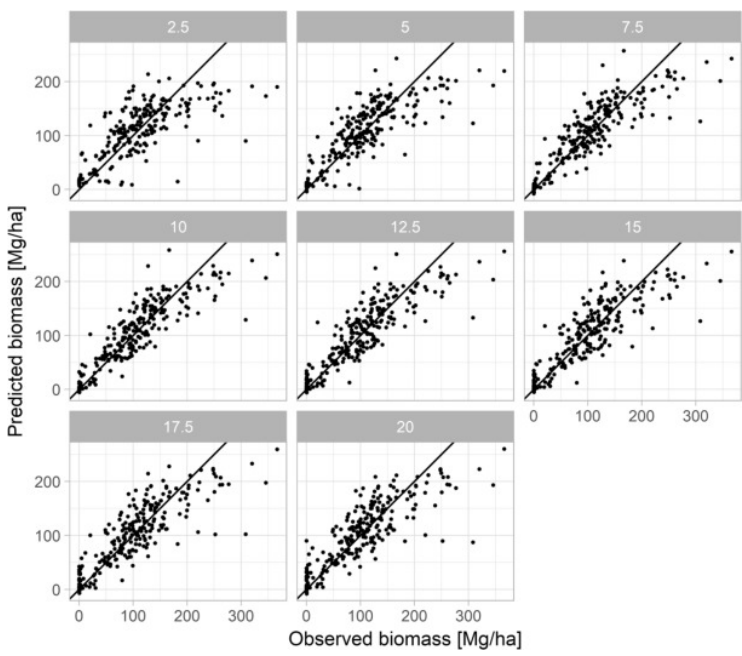

Figure A 1:Model validation - footprint size. Graphs of predicted vs. observed AGB, here for the footprint size waveform sets. The radius of the footprint is given above the single scatter plots in $\mathrm{m}$. The radius of the field plots was $10 \mathrm{~m}$.

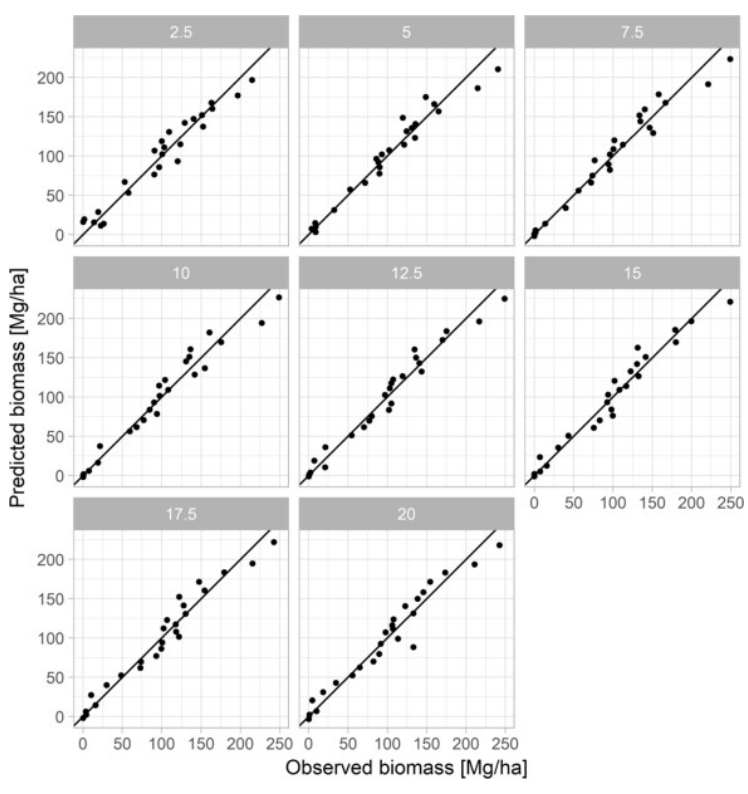

Figure A2: Model validation - footprint size. Group means of predicted vs. observed AGB, here for the footprint size waveform sets. The radius of the footprint is given above the single scatter plots in $\mathrm{m}$. The radius of the field plots was $10 \mathrm{~m}$.

\section{Appendix B}

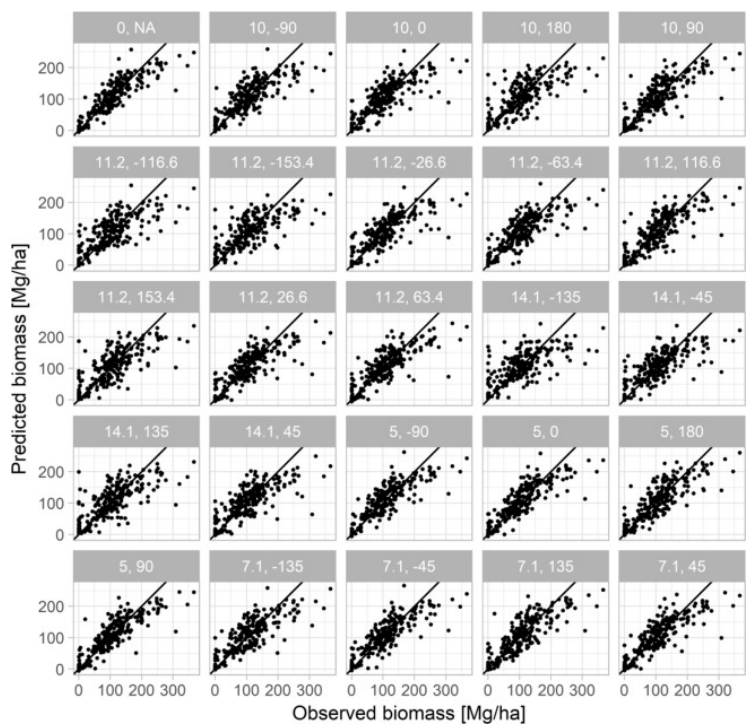

Figure B1: Model validation - Geolocation error. Graphs of predicted vs. observed AGB, here for the geolocation error waveform sets. Above the single scatter plots the displacement distance in $\mathrm{m}$ and the direction of displacement in degrees are given. The footprint radius was fixed to $10 \mathrm{~m}$, and the field plot radius was $10 \mathrm{~m}$.

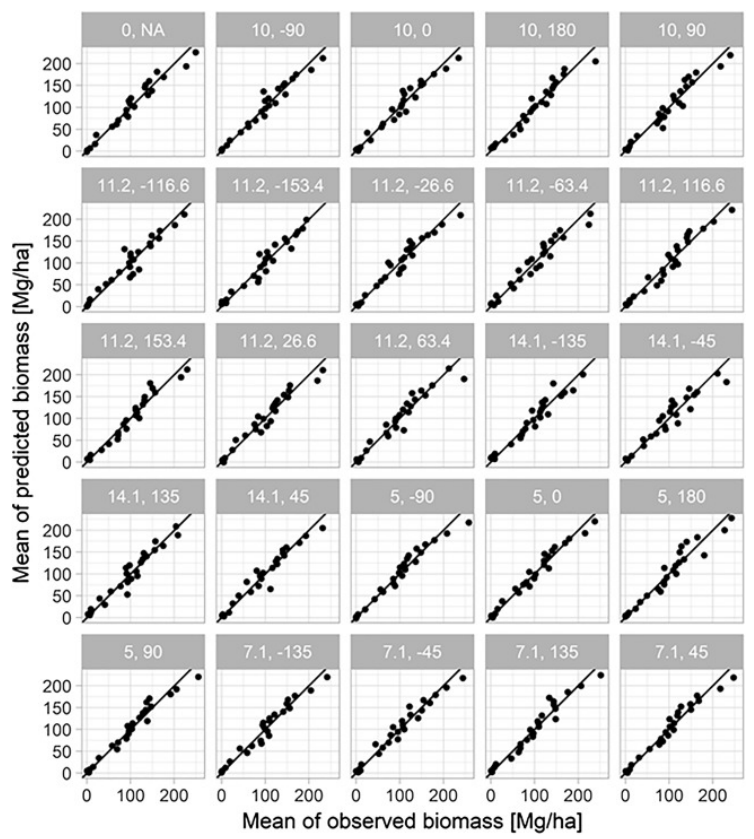

Figure B2: Model validation - Geolocation error. Group means of predicted vs. observed AGB, here for the geolocation error waveform sets. Above the single scatter plots the displacement distance in $\mathrm{m}$ and the direction of displacement 
in degrees are given. The footprint radius was fixed to $10 \mathrm{~m}$, and the field plot radius was $10 \mathrm{~m}$.

\section{References}

Abdalati, W., Zwally, H.J., Bindschadler, R., Csatho, B., Farrell, S.L., Fricker, H.A., Harding, D., Kwok, R., Lefsky, M., Markus, T., Marshak, A., Neumann, T., Palm, S., Schutz, B., Smith, B., Spinhirne, J., \& Webb, C. (2010). The ICESat-2 Laser Altimetry Mission. Proceedings of the IEEE, 98, 735-751

Axelsson, P.E. (1999). Processing of laser scanner data - algorithms and applications. Isprs Journal of Photogrammetry and Remote Sensing, 54, 138-147

Blair, J.B., \& Hofton, M.A. (1999). Modeling laser altimeter return waveforms over complex vegetation using high-resolution elevation data. Geophysical Research Letters, 26, 2509-2512

Boudreau, J., Nelson, R., Margolis, H., Beaudoin, A., Guindon, L., \& Kimes, D. (2008). Regional aboveground forest biomass using airborne and spaceborne LiDAR in Québec. Remote Sensing of Environment, 112, 3876-3890

Duong, H., Lindenbergh, R., Pfeifer, N., \& Vosselman, G. (2009). ICESat Full-Waveform Altimetry Compared to Airborne Laser Scanning Altimetry Over The Netherlands. Ieee Transactions on Geoscience and Remote Sensing, 47, 3365-3378

Ene, L.T., Næsset, E., Gobakken, T., Gregoire, T.G., Ståhl, G., \& Holm, S. (2013). A simulation approach for accuracy assessment of two-phase post-stratified estimation in largearea LiDAR biomass surveys. Remote Sensing of Environment, 133, 210-224

Frazer, G.W., Magnussen, S., Wulder, M.A., \& Niemann, K.O. (2011). Simulated impact of sample plot size and co-registration error on the accuracy and uncertainty of LiDAR-derived estimates of forest stand biomass. Remote Sensing of Environment, 115, 636-649

Gastellu-Etchegorry, J.P., Yin, T.G., Lauret, N., Cajgfinger, T., Gregoire, T., Grau, E., Feret, J.B., Lopes, M., Guilleux, J., Dedieu, G., Malenovsky, Z., Cook, B.D., Morton, D., Rubio, J., Durrieu, S., Cazanave, G., Martin, E., \& Ristorcelli, T. (2015). Discrete Anisotropic Radiative Transfer (DART 5) for Modeling Airborne and Satellite Spectroradiometer and LIDAR Acquisitions of Natural and Urban Landscapes. Remote Sensing, 7, 1667-1701

Gobakken, T., \& Næsset, E. (2009). Assessing effects of positioning errors and sample plot size on biophysical stand properties derived from airborne laser scanner data. Canadian Journal of Forest Research, 39, 1036-1052

Goncalves, F., Treuhaft, R., Law, B., Almeida, A., Walker, W., Baccini, A., dos Santos, J.R., \& Graca, P. (2017). Estimating Aboveground Biomass in Tropical Forests: Field Methods and Error Analysis for the Calibration of Remote Sensing Observations. Remote Sensing, 9

Gregoire, T.G., Stahl, G., Naesset, E., Gobakken, T., Nelson, R., \& Holm, S. (2011). Model-assisted estimation of biomass in a LiDAR sample survey in Hedmark County, Norway. Canadian Journal of Forest Research-Revue Canadienne De Recherche Forestiere, 41, 83-95

Gwenzi, D., Lefsky, M.A., Suchdeo, V.P., \& Harding, D.J. (2016). Prospects of the ICESat-2 laser altimetry mission for savanna ecosystem structural studies based on airborne simulation data. Isprs Journal of Photogrammetry and Remote Sensing, 118, 68-82

Hall, F.G., Bergen, K., Blair, J.B., Dubayah, R., Houghton, R., Hurtt, G., Kellndorfer, J., Lefsky, M., Ranson, J., Saatchi, S., Shugart, H.H., \& Wickland, D. (2011). Characterizing $3 \mathrm{D}$ vegetation structure from space: Mission requirements. Remote Sensing of Environment, 115, 2753-2775

Holm, S., Nelson, R., \& Ståhl, G. (2017). Hybrid three-phase estimators for large-area forest inventory using ground plots, airborne lidar, and space lidar. Remote Sensing of Environment, 197, 85-97

Lefsky, M.A. (2010). A global forest canopy height map from the Moderate Resolution Imaging Spectroradiometer and the Geoscience Laser Altimeter System: A GLOBAL FOREST CANOPY HEIGHT MAP. Geophysical Research Letters, 37, n/a-n/a

Lefsky, M.A., Harding, D., Cohen, W.B., Parker, G., \& Shugart, H.H. (1999). Surface lidar remote sensing of basal area and biomass in deciduous forests of eastern Maryland, USA. Remote Sensing of Environment, 67, 83-98

Lu, H., Pang, Y., Li, Z.Y., \& Chen, B.W. (2015). An Automatic Range Ambiguity Solution in High-Repetition-Rate Airborne Laser Scanner Using Priori Terrain Prediction. Ieee Geoscience and Remote Sensing Letters, 12, 22322236

Magnussen, S. (2015). Arguments for a model-dependent inference? Forestry: An International Journal of Forest Research, 88, 317-325

Magnussen, S., Frazer, G., \& Penner, M. (2016). Alternative mean-squared error estimators for synthetic estimators of domain means. Journal of Applied Statistics, 43, 25502573

Mandallaz, D. (2008). Sampling techniques for forest inventories. Boca Raton, FL: Chapman \& Hall/CRC

Margolis, H.A., Nelson, R.F., Montesano, P.M., Beaudoin, A., Sun, G., Andersen, H.-E., \& Wulder, M.A. (2015). Combining satellite lidar, airborne lidar, and ground plots to estimate the amount and distribution of aboveground biomass in the boreal forest of North America. Canadian Journal of Forest Research, 45, 838-855

Marklund, L.G. (1988). Biomass functions for pine, spruce and birch in Sweden. In: Dep. of For. Surv.

Maselli, F., Chiesi, M., Mura, M., Marchetti, M., Corona, P., \& Chirici, G. (2014). Combination of optical and LiDAR satellite imagery with forest inventory data to improve wall-to-wall assessment of growing stock in Italy. International Journal of Applied Earth Observation and Geoinformation, 26, 377-386

MATLAB (2016). Signal Processing Toolbox: Release Notes (R2016b). In: The MathWorks

McCulloch, C.E., Searle, S.R., \& Neuhaus, J.M. (2008). Generalized, linear, and mixed models. (2nd ed ed.). Hoboken, N.J: Wiley

McRoberts, R.E., Naesset, E., \& Gobakken, T. (2013). Accuracy and Precision for Remote Sensing Applications of Nonlinear Model-Based Inference. IEEE Journal of Selected Topics in Applied Earth Observations and Remote Sensing, 6, 27-34

Montesano, P.M., Rosette, J., Sun, G., North, P., Nelson, R.F., Dubayah, R.O., Ranson, K.J., \& Kharuk, V. (2015). The uncertainty of biomass estimates from modeled ICESat-2 returns across a boreal forest gradient. Remote Sensing of Environment, 158, 95-109 
NASA (2016). GEDI - High Resolution Ranging of Earth's Forests and Topography On ISS. In: NASA Science

Neigh, C.S.R., Nelson, R.F., Ranson, K.J., Margolis, H.A., Montesano, P.M., Sun, G., Kharuk, V., Næsset, E., Wulder, M.A., \& Andersen, H.-E. (2013). Taking stock of circumboreal forest carbon with ground measurements, airborne and spaceborne LiDAR. Remote Sensing of Environment, 137, 274-287

Nelson, R., Boudreau, J., Gregoire, T.G., Margolis, H., Næsset, E., Gobakken, T., \& Ståhl, G. (2009). Estimating Quebec provincial forest resources using ICESat/GLAS. Canadian Journal of Forest Research, 39, 862-881

Nelson, R., Margolis, H., Montesano, P., Sun, G., Cook, B., Corp, L., Andersen, H.-E., deJong, B., Pellat, F.P., Fickel, T., Kauffman, J., \& Prisley, S. (2017). Lidar-based estimates of aboveground biomass in the continental US and Mexico using ground, airborne, and satellite observations. Remote Sensing of Environment, 188, 127-140

North, P.R.J., Rosette, J.A.B., Suarez, J.C., \& Los, S.O. (2010). A Monte Carlo radiative transfer model of satellite waveform LiDAR. International Journal of Remote Sensing, 31, 1343-1358

Pang, Y., Lefsky, M., Sun, G., \& Ranson, J. (2011). Impact of footprint diameter and off-nadir pointing on the precision of canopy height estimates from spaceborne lidar. Remote Sensing of Environment, 115, 2798-2809

Pinheiro, J., Bates, D., DebRoy, S., Sarkar, D., \& Team, R.C. (2016). nlme: Linear and Nonlinear Mixed Effects Models.

Popescu, S.C., Zhao, K., Neuenschwander, A., \& Lin, C. (2011). Satellite lidar vs. small footprint airborne lidar: Comparing the accuracy of aboveground biomass estimates and forest structure metrics at footprint level. Remote Sensing of Environment, 115, 2786-2797

Rejou-Mechain, M., Muller-Landau, H.C., Detto, M., Thomas, S.C., Le Toan, T., Saatchi, S.S., Barreto-Silva, J.S., Bourg, N.A., Bunyavejchewin, S., Butt, N., Brockelman, W.Y., Cao, M., Cardenas, D., Chiang, J.M., Chuyong, G.B., Clay, K., Condit, R., Dattaraja, H.S., Davies, S.J., Duque, A., Esufali, S., Ewango, C., Fernando, R.H.S., Fletcher, C.D., Gunatilleke, I.A.U.N., Hao, Z., Harms, K.E., Hart, T.B., Herault, B., Howe, R.W., Hubbell, S.P., Johnson, D.J., Kenfack, D., Larson, A.J., Lin, L., Lin, Y., Lutz, J.A., Makana, J.R., Malhi, Y., Marthews, T.R., McEwan, R.W., McMahon, S.M., McShea, W.J., Muscarella, R., Nathalang, A., Noor, N.S.M., Nytch, C.J., Oliveira, A.A., Phillips, R.P., Pongpattananurak, N., Punchi-Manage, R.,
Salim, R., Schurman, J., Sukumar, R., Suresh, H.S., Suwanvecho, U., Thomas, D.W., Thompson, J., Uriarte, M., Valencia, R., Vicentini, A., Wolf, A.T., Yap, S., Yuan, Z., Zartman, C.E., Zimmerman, J.K., \& Chave, J. (2014). Local spatial structure of forest biomass and its consequences for remote sensing of carbon stocks. Biogeosciences, 11, 6827-6840

Rieger, P., \& Ullrich, A. (2011). Resolving range ambiguities in high-repetition rate airborne lidar applications. In (pp. 81860A-81860A-81868)

Riegl (2013). Waveform Extraction Library. In. Horn, Austria, Printed on: March, 18. 2013 C RIEGL Laser Measurement Systems GmbH

Saarela, S., Holm, S., Grafström, A., Schnell, S., Næsset, E., Gregoire, T.G., Nelson, R.F., \& Ståhl, G. (2016a). Hierarchical model-based inference for forest inventory utilizing three sources of information. Annals of Forest Science, 73, 895-910

Saarela, S., Schnell, S., Tuominen, S., Balázs, A., Hyyppä, J., Grafström, A., \& Ståhl, G. (2016b). Effects of positional errors in model-assisted and model-based estimation of growing stock volume. Remote Sensing of Environment, $172,101-108$

Ståhl, G., Saarela, S., Schnell, S., Holm, S., Breidenbach, J., Healey, S.P., Patterson, P.L., Magnussen, S., Næsset, E., McRoberts, R.E., \& Gregoire, T.G. (2016). Use of models in large-area forest surveys: comparing model-assisted, model-based and hybrid estimation. Forest Ecosystems, 3, $1-11$

Sun, G., Ranson, K.J., Kimes, D.S., Blair, J.B., \& Kovacs, K. (2008). Forest vertical structure from GLAS: An evaluation using LVIS and SRTM data. Remote Sensing of Environment, 112, 107-117

Tomppo, E., Gschwantner, T., \& Lawrence, M. (2010). National Forest Inventories. Springer Netherlands

Wagner, W., Ullrich, A., Ducic, V., Melzer, T., \& Studnicka, N. (2006). Gaussian decomposition and calibration of a novel small-footprint full-waveform digitising airborne laser scanner. Isprs Journal of Photogrammetry and Remote Sensing, 60, 100-112

Wulder, M.A., White, J.C., Nelson, R.F., Næsset, E., Ørka, H.O., Coops, N.C., Hilker, T., Bater, C.W., \& Gobakken, T. (2012). Lidar sampling for large-area forest characterization: A review. Remote Sensing of Environment, 121, 196-209 